struction, or both. ${ }^{2,3}$ Furthermore, in developing countries percutaneous laser- or radiofrequency-assisted perforation for neonates is far from popular and can be performed in very few centers. Hence, in general neonates with PAIVS were referred to the surgical department in our center. Surgical approaches, including RVOT reconstruction with a transannular patch and transventricular/pulmonary valvotomy, were also attempted to achieve right ventricular decompression; however, the mortality was considerably high. ${ }^{4}$ Based on the above facts, we integrated the catheterbased devices and the traditional surgical procedure for PAIVS as initial management.

In this hybrid beating-heart procedure, first we perforate the PV with the needle and then deliver the balloon through the RV free wall to the pulmonary trunk. Epicardial echocardiography was used not only to guide the procedure with real-time imaging but also to evaluate the effectiveness of valvuloplasty with monitoring of the trans-PV flow and gradient pressure. In percutaneous catheter therapy, if the newborn could not be weaned from the prostaglandin infusion, an urgent BT shunt would be considered. Such a delayed decision could result in postoperative hypoxia and thus increased mortality. Because the operative field was offered by the open-chest approach, we regularly placed a BT shunt simultaneously. Ligation of the patent ductus arteriosus was performed to prevent the excess augmentation of blood flow to the lung, and then prostaglandin infusion was ceased immediately in the operating room.
We have not yet applied the hybrid procedure for PAIVS in a patient with a severely hypoplastic RV. Theoretically, such a hybrid procedure would augment the antegrade flow and offer the chance of development of the RV; therefore it was also beneficial for this subgroup.

In conclusion, our results show that, combined with real-time echocardiographic guidance and a catheter-based device, the hybrid procedure could be a good alternative to percutaneous catheter-based therapy for selected neonates with PAIVS, especially in centers in developing countries where the materials for percutaneous perforation are not available and the experience with neonatal percutaneous catheter therapy is limited.

We thank the National Eleventh-Five Year Project and Beijing Nova Project (2006 A85).

\section{References}

1. Humpl T, Söderberg B, McCrindle BW, Nykanen DG, Freedom RM, Williams WG, et al. Percutaneous balloon valvotomy in pulmonary atresia with intact ventricular septum: impact on patient care. Circulation. 2003;108:826-32.

2. Mclean KM, Pearl JM. Pulmonary atresia with intact ventricular septum: initial management. Ann Thorac Surg. 2006;82:2214-20.

3. Agnoletti G, Piechaud JF, Bonhoeffer P, Aggoun Y, Abdel-Massih T, Boudjemline $Y$, et al. Perforation of the atretic pulmonary valve: longtime follow up. J Am Coll Cardiol. 2003;41:1399-403.

4. Bull C, Kostelka M, Sorensen K, de Leval. Outcome measures for the neonatal management of pulmonary atresia with intact ventricular septum. J Thorac Cardiovasc Surg. 1994;107:359-66.

\title{
Reduced regional right ventricular wall motion after transventricular repair of tetralogy of Fallot
}

\author{
Shin Takabayashi, MD, PhD, ${ }^{a}$ Hideto Shimpo, MD, PhD, ${ }^{a}$ Kazuto Yokoyama, MD, ${ }^{a}$ Koji Onoda, MD, PhD, and \\ Yoshihide Mitani, MD, PhD, ${ }^{\mathrm{b}}$ Mie, Japan
}

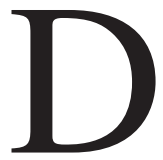

uring intracardiac repair of tetralogy of Fallot (TOF), a larger right ventriculotomy provides better exposure of ventricular structures. However, right ventricular (RV) function is impaired after ventriculotomy, and a previous report suggests that ventriculotomy reduces regional wall

From the Departments of Thoracic and Cardiovascular Surgery a and Pediatrics, ${ }^{\text {b }}$ Mie University Graduate School of Medicine, Mie, Japan.

Received for publication Feb 19, 2006; accepted for publication March 5, 2006.

Address for reprints: Shin Takabayashi, MD, Department of Thoracic and Cardiovascular Surgery, Mie University Graduate School of Medicine, 2-174, Edobashi, Tsu, Mie 514-8507, Japan (E-mail: shin1111@clin.medic.mie-u.ac.jp).

J Thorac Cardiovasc Surg 2007;133:1656-8

$0022-5223 / \$ 32.00$

Copyright $\odot 2007$ by The American Association for Thoracic Surgery doi:10.1016/j.jtcvs.2007.03.001 motion around the $\mathrm{RV}$ incision. ${ }^{1}$ To investigate the impact of right ventriculotomy on regional $\mathrm{RV}$ wall function, we used postoperative lateral RV angiocardiography to compare segmental fractional shortening (FS) after transventricular and transpulmonarytransatrial TOF repair.

\section{Clinical Summary}

We studied 28 consecutive patients who underwent TOF repair between 1994 and 1998. They were divided into two groups: the first 14 patients underwent transventricular repair (group V) and the other 14 underwent transatrial-transpulmonary repair (group A). The mean age (2.9 vs 2.6 years), weight (13.0 vs $11.4 \mathrm{~kg}$ ) and preoperative RV function were not significantly different between group $\mathrm{V}$ and group $\mathrm{A}$. Three patients in group $\mathrm{V}$ had undergone a prior operation (systemic-pulmonary shunt, 2; Brock, 1), and 1 patient in group A had undergone a systemic-pulmonary shunt. A transannular patch repair was performed in 9 patients in each group. Definitive repair by ven- 

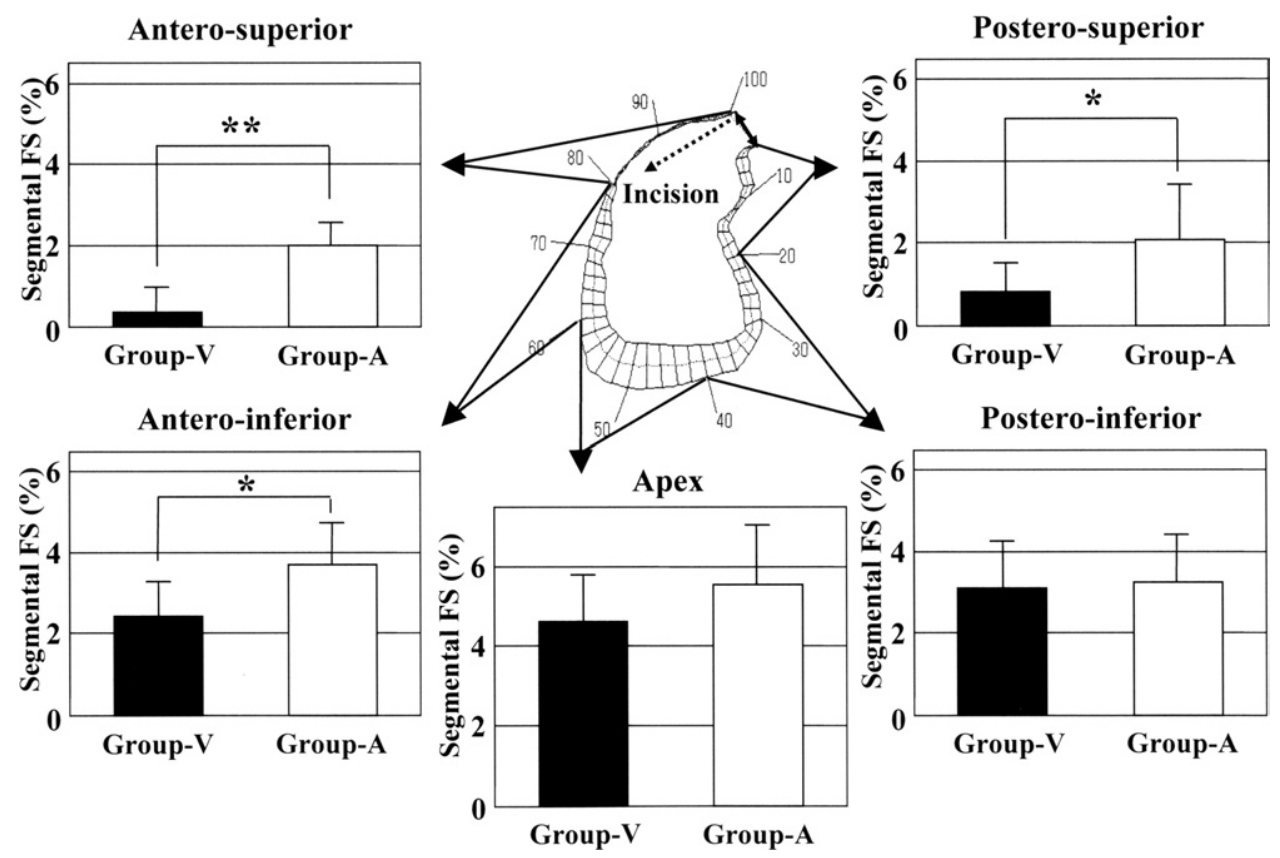

Figure 1. Schema of regional wall motion assessed by the centerline method, and comparison of regional right ventricular wall motion between group $\mathbf{V}$ and group $\mathrm{A}$. FS, Fractional shortening, ${ }^{*} \boldsymbol{P}<.01,{ }^{*} \boldsymbol{P}<.05$.

tricular septal defect closure was performed through a $15-$ to 20-mm RV incision in group V. A limited RV incision $(<10$ $\mathrm{mm}$ ) was performed in the patients in group A who underwent a transannular patch repair. We performed muscle resection of the RV outflow tract (except the ventricular septum) in both groups.

There were no postoperative deaths. Echocardiography at the time of discharge showed pulmonary stenosis $(>30 \mathrm{~mm} \mathrm{Hg})$ in 2 patients in each group and pulmonary insufficiency ( $>$ moderate) in 3 patients in group $\mathrm{V}$ and 2 patients in group $\mathrm{A}$.

Angiocardiography (median 1.2 months after the operation) showed that although the RV end-diastolic volume by the Simpson method was similar in group V and group A (93 vs $\left.86 \mathrm{~mL} / \mathrm{m}^{2}\right)$, the $\mathrm{RV}$ ejection fraction was lower in group $\mathrm{V}$ than in group $\mathrm{A}$ $(48 \% \pm 9 \%$ vs $63 \% \pm 10 \%: P<.05)$, and the RV end-diastolic pressure was higher in group $\mathrm{V}$ than in group A (9.3 vs 4.3 $\mathrm{mm} \mathrm{Hg} ; P<.05)$. To investigate the postoperative regional $\mathrm{RV}$ wall motion, we used the centerline method to calculate segmental FS on lateral RV angiocardiography. ${ }^{2} \mathrm{We}$ assessed $5 \mathrm{RV}$ areas, determining the mean value of each 20/100 of segmental FS (anterosuperior, 80-100; anteroinferior, 60-80; apex, 40-60; posteroinferior, 20-40; and posterosuperior, 0-20), and compared regional RV wall motion between group $\mathrm{V}$ and group $\mathrm{A}$ (Figure 1). Regional wall motion of the anterosuperior area (the site of ventriculotomy) was significantly lower in group $\mathrm{V}$ than in group $\mathrm{A}$ $(0.3 \% \pm 0.6 \%$ vs $2.0 \% \pm 0.6 \% ; P<.01)$. Although wall motion of the apex $(4.6 \% \pm 1.6 \%$ vs $5.6 \% \pm 1.8 \%)$ and posteroinferior area $(3.1 \% \pm 2.2 \%$ vs $3.2 \% \pm 2.2 \%)$ was similar in group V and group A, wall motion of the anteroinferior $(2.4 \% \pm 1.0 \%$ vs $3.7 \% \pm 1.0 \% ; P<.05)$ and posterosuperior areas $(0.8 \% \pm$
$0.8 \%$ vs $2.1 \% \pm 1.4 \% ; P<.05)$ was significantly lower in group $\mathrm{V}$ than group $\mathrm{A}$.

\section{Discussion}

Although the right ventriculotomy used for TOF repair inevitably impairs the postoperative RV function to some degree, impaired regional RV function could not be clearly detected by early ${ }^{3}$ or late ${ }^{4}$ clinical outcomes, and detailed analysis of postoperative regional $\mathrm{RV}$ function after ventriculotomy has not been well described.

Our analysis of segmental FS using the centerline method showed that RV wall motion of the anteroinferior and posterosuperior areas, as well as the ventriculotomy site, was more reduced in the transventricular repair group than the transatrialtranspulmonary repair group. Although our study is not a quantitative analysis because the lateral view of the right ventriculography was not expressed as 3-dimensional RV function, these results suggest that reduction of the whole RV function (ejection fraction and end-diastolic pressure) would be brought about by reduction of regional $\mathrm{RV}$ function at the site of the ventriculotomy, as well as the surrounding areas of the right ventricle. The cause of reduced RV wall motion around the ventriculotomy site is multifactorial. One of the mechanisms involved is the architecture of the cardiac muscle fibers in the TOF heart. The superficial muscle layer has a more oblique orientation in the TOF heart than the normal heart, and a middle horizontal layer has been found in the RV wall that does not exist in the normal heart. ${ }^{5}$ These may play an important role in postoperative regional RV contractility around the ventriculotomy. 
Reduction of regional RV function can occur around the ventriculotomy site after TOF repair. So that postoperative RV function will be preserved, ventriculotomy should be minimal and performed only if necessary.

\section{References}

1. Miura T, Nakano S, Shimazaki Y, Kobayashi J, Hirose H, Sano T, et al. Evaluation of right ventricular function by regional wall motion analysis in patients after correction of tetralogy of Fallot: comparison of transventricular and nontransventricular repairs. J Thorac Cardiovasc Surg. 1992;104:917-23.
2. Sheehan FH, Bolson EL, Dodge HT, Mathey DG, Schofer J, Woo HW. Advantages and applications of the centerline method for characterizing regional ventricular function. Circulation. 1986; 74:293-305.

3. Alexiou C, Chen Q, Galogavrou M, Gnanapragasam J, Salmon AP, Keeton BR, et al. Repair of tetralogy of Fallot in infancy with a transventricular or a transatrial approach. Eur J Cardiothorac Surg. 2002;22:174-83.

4. d'Udekem Y, Ovaert C, Grandjean F, Gerin V, Cailteux M, ShangoLody P, et al. Tetralogy of Fallot: transannular and right ventricular patching equally affect late functional status. Circulation. 2000; 102(Suppl 3):III116-22.

5. Sanchez-Quintana D, Anderson RH, Ho SY. Ventricular myoarchitecture in tetralogy of Fallot. Heart. 1996;76:280-6.

\title{
Cervical ectopic thymoma
}

\author{
I-Lin Hsu, MD, ${ }^{\text {b }}$ Ming-Ho Wu, MD, ${ }^{a}$ Wu-Wei Lai, MD, ${ }^{a}$ Mu-Yen Lin, MD, ${ }^{a}$ Jia-Ming Chang, MD, ${ }^{a}$ Yi-Ting Yen, MD, and \\ Yau-Lin Tseng, MD, ${ }^{a}$ Tainan, Taiwan
}

T

he thymus develops from the third and fourth brachial clefts and descends into the anterior mediastinum by the sixth week of gestation. Thymic ectopia results from hypoplasia, failure of descent, and dislocation of thymus along the path of descent. ${ }^{1}$ Cervical ectopic thymoma is extremely rare, and only 23 cases were reported until 2005 . $^{2}$ Most cases occur in women and generally present with a mass in the neck, often confused clinically with a thyroid nodule. Preoperative diagnosis is difficult even with aspiration biopsy. We present 2 patients with cervical ectopic thymoma; one is type $\mathrm{AB}$ and the other is type $\mathrm{C}$ (thymic carcinoma).

\section{Clinical Summaries}

CASE 1: A 55-year-old woman had a palpable neck mass for 20 years. She visited the General Surgery department because of recent dyspnea. Chest radiograph revealed cervical tracheal deviation by tumor compression. The echo with color Doppler showed a 7-cm heterogeneous, hypoechoic, and hypervascular tumor in the suprasternal notch; the thyroid gland was of normal size and echo pattern. Computed tomography revealed a large neck mass adhering to the thyroid with external compression of

\footnotetext{
From the Departments of Surgery ${ }^{\mathrm{a}}$ and Emergency, ${ }^{\mathrm{b}}$ Division of Thoracic Surgery, National Cheng Kung University Hospital, Tainan, Taiwan.

Received for publication Nov 30, 2006; accepted for publication Jan 23, 2007.

Address for reprints: Yau-Lin Tseng, Division of Thoracic Surgery, Department of Surgery, National Cheng Kung University Hospital, Tainan, Taiwan. (E-mail: tsengyl@mail.ncku.edu.tw).

J Thorac Cardiovasc Surg 2007;133:1658-9

$0022-5223 / \$ 32.00$

Copyright (C) 2007 by The American Association for Thoracic Surgery doi:10.1016/j.jtcvs.2007.01.037
}

the cervical trachea (Figure 1, $A$ and $B$ ). We performed tumor resection and thymectomy. The yellowish encapsulated tumor, measuring $7.0 \times 5.5 \times 3.0 \mathrm{~cm}$, was beneath the thyroid gland, without contact. Pathology revealed that it was a stage I type AB thymoma. Postoperative recovery was good, and there has been no recurrence after follow-up of 7 months

CASE 2: A 49-year-old man had hoarseness for 3 months. He visited an ear, nose, and throat clinic where left vocal cord palsy and a $3 \times 2 \mathrm{~cm}$ palpable mass on the neck were found. Chest radiograph revealed a mass on the lower neck with compressive deviation of the trachea. Computed tomography showed a neck mass, lateral to the cervical trachea, near the lower pole of left thyroid with recurrent laryngeal nerve and esophageal involvement (Figure 2, $A$ and $B$ ). He was referred to our department for further management. Bronchoscopy and esophagoscopy revealed that there was no intraluminal invasion of tumor. After discussion with the patient, on the lower neck a T-shape incision was performed to resect the tumor and obtain final diagnosis. En bloc resection was performed and included partial thyroidectomy, tumor resection, sacrifice of nonfunctional left recurrent laryngeal nerve, partial resection of muscular layer of esophagus, and left neck lymph node dissection. Frozen section of the mass showed a squamous cell carcinoma, which was CD5 positive on an immunohistochemical stain and invaded surrounding adipose tissue and muscular layer of the esophagus. Thymectomy was then performed. Final pathology revealed that in addition to the main $4.6 \times 4.2 \mathrm{~cm}$ tumor on the neck, there was a small $0.15-\mathrm{cm}$ thymic carcinoma in the remnant mediastinal thymus. One of 8 cervical lymph nodes was metastatic. The thyroid was adhered to the tumor but was not invaded. The patient was discharged uneventfully 1 week after operation. Postoperative chemotherapy (carboplatin, ifosfamide, and 5-fluorouracil) was given for 3 courses followed by mediastinal and neck 4500 cGy of radiotherapy. He was well without recurrence at 26-month follow-up. 